\title{
CXCL9, CXCL10, CXCL11, and their receptor (CXCR3) in neuroinflammation and neurodegeneration
}

\author{
Olga M. Koper ${ }^{1, A-D, F}$, Joanna Kamińska ${ }^{1, B, C, E, F}$, Karol Sawicki2, ${ }^{2, E, F}$, Halina Kemona ${ }^{1, E, F}$ \\ ${ }^{1}$ Department of Clinical Laboratory Diagnostics, Medical University of Bialystok, Poland \\ ${ }^{2}$ Department of Neurosurgery, Medical Clinical Hospital in Bialystok, Poland \\ A - research concept and design; $\mathrm{B}$ - collection and/or assembly of data; $\mathrm{C}$ - data analysis and interpretation; \\ $D$ - writing the article; $E$ - critical revision of the article; $F$ - final approval of the article
}

\section{Address for correspondence}

Olga M. Koper

E-mail: 0.koper@wp.pl

Funding sources

None declared

\section{Conflict of interest}

None declared

\section{Acknowledgements}

The authors are grateful to Piotr Abramowicz

for his technical help in preparing the figure.

Received on April 18, 2016

Reviewed on September 15, 2016

Accepted on February 7, 2017

\begin{abstract}
The aim of this review is to present data from the available literature concerning CXCL9, CXCL10 and CXCL11, as well as their receptor 3 (CXCR3) in selected diseases of the central nervous system (CNS), such as tickborne encephalitis (TBE), neuroborreliosis (NB), Alzheimer's disease (AD), and multiple sclerosis (MS). CXCL9, CXCL10, and CXCL11 lack glutamic acid-leucine-arginine (ELR), and are unique, because they are more closely related to each other than to any other chemokine. The aforementioned chemokines are especially involved in Th1-type response and in various diseases, as their expression correlates with the tissue infiltration of T cells. Their production is strongly induced by interferon gamma (IFN-Y), the most typical Th1 cytokine. They act by binding to the CXC3 receptor. Knowledge about the action mechanism of CXCR3 and its ligands may be useful in the treatment of CNS diseases. However, data in the literature concerning the evaluation of CXCL9, CXCL10, CXCL11, and their receptor with the use of the enzyme-linked immunosorbent assay (ELISA) method is limited.
\end{abstract}

Key words: chemokines, neurodegeneration, neuroinflammation, CXCR3

DOI

10.17219/acem/68846

Copyright

Copyright by Author(s)

This is an article distributed under the terms of the

Creative Commons Attribution Non-Commercial License

(http://creativecommons.org/licenses/by-nc-nd/4.0/) 


\section{Introduction}

Chemokines are crucial proteins that take part in the regulation of the migration of leukocytes in peripheral lymphatic organs. In pathological conditions, they take part in the migration of immunocompetent cells to the sites of inflammation and are also involved in neoplastic processes, or even may provide an entrance for pathogens into the body. ${ }^{1}$

The literature indicates that chemokines and their receptors might also play a role in the central nervous system (CNS). They are constitutively present in the brain on glial cells and neurons, take part in intracellular communication, and play a pivotal role during the pathogenesis of various CNS diseases. ${ }^{2-4}$ Central nervous system cells, upon stimulation by pathogens, release chemokines and are able to respond to them using their receptors. Under normal conditions, the CNS is an immune-privileged site because of a highly selective blood-brain barrier (BBB), separating the brain from the circulating blood. A pathological process leads to the activation of microglia, and this leads to neuronal and glial cell injury, as well as to death through the production of chemokines. These events enable the migration of immune cells across the BBB. ${ }^{4}$

This review is focused on CXCL9/MIG (monokineinduced by IFN- $\Upsilon$ ), CXCL10/IP-10 (interferon-inducible $10 \mathrm{kDa}$ protein) and CXCL11/I-TAC (inducible T cell- $\alpha$ chemoattractant), and their chemokine (C-X-C motif) receptor 3 (CXCR3/CD183)., ${ }^{3,5}$ Our aim is to present the data available in the literature, concerning the abovementioned chemokines and their receptor in selected CNS diseases, such as tick-borne encephalitis (TBE), neuroborreliosis (NB), Alzheimer's disease (AD), and multiple sclerosis (MS). These CNS diseases have different etiologies: $\mathrm{TBE}$ is the most common viral tick-borne disease, NB is the most common bacterial disease transmitted by ticks and $\mathrm{AD}$ is the most common form of dementia in elderly people, while MS is the most common disabling inflammatory demyelinating CNS disease in young adults. The cells of the CNS are capable of releasing chemokines upon stimulation; moreover, CNS cells are also able to respond to them by their receptors. There is evidence which identifies chemokines and their receptors as potential therapeutic targets. ${ }^{4}$ According to the best of our knowledge and the available literature, data regarding the role and evaluation of concentrations of CXCL9, CXCL10 and CXCL11, and their receptor in CNS diseases is limited and not well-studied.

\section{Chemokines}

Chemokines are small proteins $(8-15 \mathrm{kDa})$, consisting of approx. 70-90 amino acids. ${ }^{1,3,7}$ Based on the position of conservative cysteines $(C)$ in their sequence, they are divided into 4 structural subfamilies: CXC (alpha), CC (beta), $\mathrm{C}$ (gamma), and CXC3 (delta). ${ }^{8,9}$ The $\mathrm{CXC}$ chemokines are additionally subdivided into those containing a glutamic acid-leucine-arginine motif (ELR) near their N-terminus and those which do not contain this motif (non-ELR). ${ }^{3}$

Chemokines were originally discovered by their adhesion, chemotaxis and leukocyte activation abilities, both in vivo and in vitro. ${ }^{2,7}$ They are also involved in immune surveillance and the location of lymphocytes $\mathrm{B}$ or $\mathrm{T}$ with an antigen. ${ }^{3,10}$ Based on their primary function, chemokines have also been classified into inflammatory chemokines, homeostatic chemokines and dual function chemokines (involved in both of the aforementioned processes). ${ }^{8}$

Chemokines mediate their function by activating 7-transmembrane $G$ protein-coupled receptors, and thus induce cells to migrate through a concentration gradient. ${ }^{1,10}$ Chemokine receptors were identified as CXCR, CCR, CR, and $\mathrm{CX}_{3} \mathrm{CR}^{11,12}$ These receptors are part of a larger superfamily, including receptors for inflammatory mediators, hormones and neurotransmitters, as well as paracrine substances. ${ }^{8}$ The conformational change of the chemokine, which makes the $\mathrm{N}$ terminus larger and more flexible, allows for receptor activation. The activation of the chemokine receptor leads to an exchange of bound GDP to GTP in the $\alpha$ subunit of the G protein, which disassociates from the receptor, and thus activates the downstream of several effector molecules, resulting in a cascade of signaling events within the cytoplasm. ${ }^{10}$

The number of chemokine receptors is significantly lower (approx. 20) than their ligands (approx. 50), which means that various chemokines share a single, common receptor. On the other hand, individual chemokines can also bind multiple receptors. Monogamous chemokine receptor-ligand interactions have been observed only in the case of CXCL12/CXCR4 and $\mathrm{CX}_{3} \mathrm{CL} 1 / \mathrm{CX}_{3} \mathrm{CR} 1{ }^{8}$

\section{CXCL9, CXCL10 and CXCL11}

CXCL9, CXCL10 and CXCL11 are the 3 chemokines that lack ELR (Glu-Leu-Arg). They are more closely related to each other than to any other chemokine, with an amino acid sequence similarity of about $40 \% .^{5}$ The CXCL9, CXCL1O and CXCL11 gene is located on chromosome $4 \mathrm{q} 21.21{ }^{12}$ The above-mentioned chemokines are especially involved in Th1 response. In various diseases, their expression correlates with the tissue infiltration of T cells. ${ }^{7}$ Under physiological conditions, they are not detectable in most non-lymphoid tissues. However, in the case of infection, immunoinflammatory response or injury, their production by blood and tissue cells is strongly induced by IFN- the most typical Th1 cytokine (Fig. 1).,

It is interesting that the actions of the individual CXCR3 ligands can be distinct: a carboxy-terminal domain is required by CXCL9 and CXCL10, while CXCL11 requires the $2^{\text {nd }}$ domain, residing in the $3^{\text {rd }}$ intracellular loop. ${ }^{3}$ CXCL9, CXCL10 and CXCL11 may also act as natural antagonists for the receptor for eotaxin (CCR3) and a few other CC chemokines. ${ }^{5}$ 
Data in the literature indicates a significant role for CXCL9, CXCL10 and CXCL11, and their receptor in the CNS, in both physiological processes and pathological processes. CXCL11 was originally identified in interferon beta (IFN- $\beta$ ) treated mouse astrocytes. It was shown that IFN- $\Upsilon$ alone or with interleukin (IL)-1 had the ability to stimulate CXCL11 gene expression by human astrocytes and fetal human microglia. Similarly, CXCL10 was identified in the context of IFN-inducible genes, expressed by murine-cultured astrocytes and microglia. CXCR3/CXCL10 signaling is crucial in microglia recruitment and essential for neuronal reorganization. ${ }^{13}$ CXCL9 is constitutively expressed on human brain-derived microvascular endothelial cells and astrocytes. ${ }^{3}$

\section{The CXC3 receptor}

CXC3 receptor (CXCR3) gene is located on chromosome $\mathrm{Xq13}$. CXCR3 is a classic 7-transmembrane receptor coupled to the $G$ protein. Historically, this was the $3^{\text {rd }}$ chemokine receptor discovered. It encloses an extracellular domain, which contains 3 potential amino-glycosylation sites, 7 transmembrane-spanning domains and intracellular carboxyl-terminal regions with 3 intracellular loop regions, and it shares a 30\% identity with CXCR1 (CD181) and CXCR2 (CD182). ${ }^{14}$

CXCR3 is linked to several pathways, including Src, PI3K and MAPK signaling pathways, and it is expressed in a few forms (CXCR3-A, CXCR3-B and CXCR3-alt). The classic form, CXCR3-A, is expressed on CD4 ${ }^{+}$Th1 cells, naïve and memory $\mathrm{CD}^{+} \mathrm{T}$ cells, natural killer (NK) cells, and activated $\mathrm{B}$ cells. It can also be induced on all $\mathrm{T}$ cell subsets within the first few days after activation. ${ }^{3,15}$ The role of CXCR3-A consists in mediating the direct migration of T cells to inflamed lymph nodes and other sites of inflammation. ${ }^{6,15}$ Studies showed that Th1 cells in vitro generate higher levels of CXC3 receptor expression and migrate better to CXCL11, CXCL10 and CXCL9 than Th2 cells. ${ }^{5}$

CXCR3-B is an alternatively spliced variant of the CXCR3 gene and it contains a longer $\mathrm{NH} 2$-terminal extracellular domain. ${ }^{3,15}$ While CXCR3-A supports cell survival and chemotaxis, the role of CXCR3-B consists in DNA synthesis inhibition and the induction of apoptosis. CXCR3-B also has an angiostatic effect on tumor-associated blood vessels and acts as a functional receptor for platelet factor 4 (CXCL4/PF4). ${ }^{6,16}$ CXCR3-alt is the $3^{\text {rd }}$ variant that contains a truncated C-terminus, as it lacks an intact $3^{\text {rd }}$ and $2^{\text {nd }}$ extracellular loop. Cells showing an expression of this form in vitro are capable of migrating in response to stimulation with CXCL11. ${ }^{15}$

\section{Tick-borne encephalitis}

Tick-borne encephalitis (TBE) is one of the most significant human arboviral infections of the CNS. ${ }^{2,17}$ It is endemic to regions where transmission vectors are distributed: Ixodes ricinus-dominated, Ixodes persulcatus-dominated

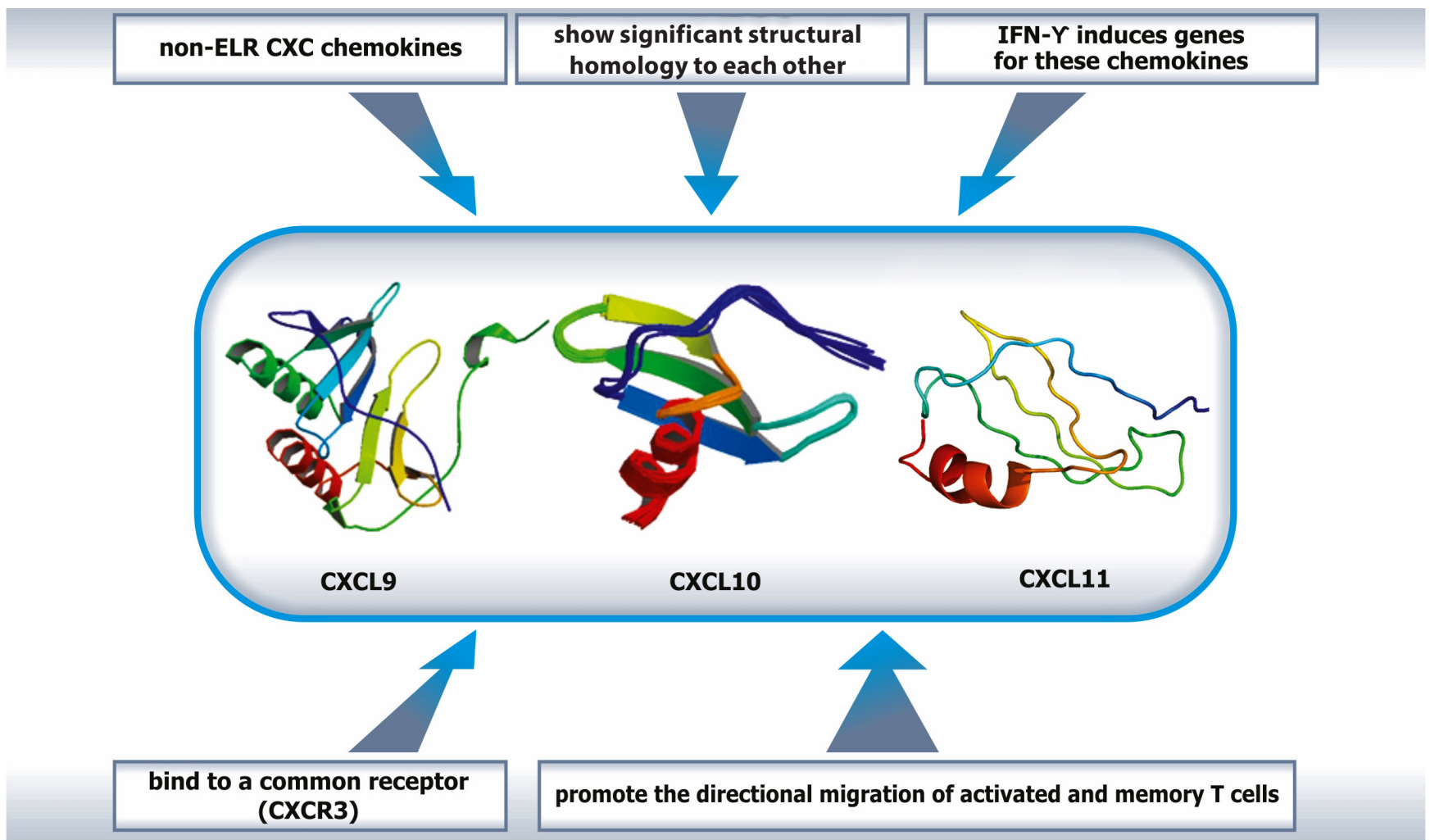

Fig. 1. The characteristics of CXCL9, CXCL10 and CXCL11 chemokines 
and mixed regions. ${ }^{17,18}$ So far, 3 genotypes of TBE viruses have been described: the European subtype transmitted by $I$. ricinus and the Siberian and Far-Eastern subtypes transmitted by $I$. persulcatus. Recently, the incidence of TBE has significantly increased, particularly in Germany, Switzerland, Lithuania, Latvia, and Poland. ${ }^{17,18}$ Approximately 40\% of infectious TBE cases might be asymptomatic; however, TBE is generally associated with a flu-like syndrome and causes moderate to severe injuries of the CNS. ${ }^{17}$ The $2^{\text {nd }}$ neurological phase may occur: with aseptic meningitis (in $50 \%$ of the cases), meningoencephalitis (40\%) or meningoencephalomyelitis (10\%). ${ }^{17}$

Chemokines are responsible for attracting leukocytes into the CNS and the cerebrospinal fluid (CSF) across the $\mathrm{BBB}$ in meningitis and meningoencephalitis. Holub et al. showed that the majority of cells in the early stage of TBE are T lymphocytes and only a small number consist of B lymphocytes and NK cells. ${ }^{19}$

There is not much data concerning the possible involvement of CXCL9, CXCL10 or CXCL11 chemokines, and their receptor in TBE. So far, the role and diagnostic usefulness of the aforementioned chemokines in TBE have been tested only by Zajkowska et al. and Koper et al. ${ }^{20,21}$ Zajkowska et al. noted that serum CXCL10 concentrations were significantly increased in the acute phase of TBE as compared to the control group. CXCL10 and CXCL11 concentrations were also significantly higher in the CSF than in the serum, which might suggest that local production in the CSF is their source. ${ }^{20}$ Moreover, the authors suggested that the concentration gradients of CXCL10 and CXCL11 between the CSF and the serum may recruit lymphocytes $\mathrm{T}$ to the CSF. Cerebrospinal fluid CXCL10 and CXCL11 concentrations were lower in TBE patients after treatment than before treatment; however, they still remained higher than in the control group (Table 1). ${ }^{20}$ With the use of receiver operator characteristic (ROC) curves, Zajkowska et al. also assessed the diagnostic usefulness of these chemokines in the diagnosis and monitoring of inflammatory process in TBE. ${ }^{20}$ The ROC curves analysis of CXCL10 and CXCL11 in TBE patients before and after treatment showed significant differences between these 2 groups. Additionally, CXCL10 and CXCL11 in the CSF were highly useful diagnostically $(\mathrm{p}<0.050)$. According to Zajkowska et al., these chemokines might be useful parameters in monitoring the course of TBE. ${ }^{20}$

CXCL9 concentrations in TBE were analyzed by Koper et al., who revealed that the CSF and serum CXCL9 levels were significantly higher as compared to the controls. Cerebrospinal fluid CXCL9 demonstrated a tendency for higher concentrations, while serum CXCL9 tended to be lower in the acute phase of TBE in comparison to the TBE patients after a 2-week follow-up. However, neither difference was statistically significant (Table 1). To exclude the possible impairment of the blood-CSF barrier and/or BBB functions as potential sources influencing CXCL9 concentrations, the authors then related CSF CXCL9 concentrations to the serum levels in order to calculate the CXCL9 index $\left(\mathrm{I}_{\mathrm{CXCL} 9}\right)$. The levels of $\mathrm{I}_{\mathrm{CXCL} 9}$ in the acute phase of TBE and after a 2-week follow-up were significantly higher compared to the controls, and significantly decreased after the resolution of the symptoms. To sum up their findings, Koper et al. concluded that the CXCL9 index may be a better indicator of symptom resolutions in TBE than CSF or serum CXCL9 concentrations. ${ }^{21}$

The data presented in Table 1 indicates that higher concentrations of CXCL9 and CXCL10 are noted in the CSF as compared to serum samples. Among all 3 chemokines presented in this review, CXCL9 seems to be more specific for TBE than CXCL10 and CXC11, regardless of the type of material obtained from the patient for analysis.

\section{Neuroborreliosis}

Borreliosis (Lyme disease, Lyme borreliosis, LB) is a chronic disease, caused by etiologic factors which are spirochaetes Borrelia burgdorferi sensu lato. Annually, there are about 85,500 LB cases reported worldwide (approx. 65,500 cases in Europe, 16,500 in North America, 3,500 in Asia). ${ }^{22}$

It is estimated that neurological forms of Lyme disease develop in about $40 \%$ of the patients suffering from B. burgdorferi. Henningsson et al. reported that the number of neuroborreliosis (NB) cases in Sweden between 2000 and 2005 increased from 5/100,000 to 10/100,000 inhabitants/year. ${ }^{23}$
Table 1. CXCL9, CXCL10 and CXCL11 tested by the ELISA method in tick-borne encephalitis. Values are expressed in $\mathrm{pg} / \mathrm{mL}$

\begin{tabular}{|c|c|c|}
\hline $\begin{array}{c}\text { Zajkowska et al., } 2011 \\
\text { TBE }(n=15) \text {, controls }(n=8)\end{array}$ & CSF & Serum \\
\hline CXCL10 & $\begin{array}{ll}\text { - } & \text { TBE1 (9360) vs C (338) - } \mathrm{p}^{*} \\
\text { - } & \text { TBE2 (1500) vs C (338) - } \mathrm{p}^{\mathrm{a}} \\
\text { - } & \text { TBE1 (9360) vs TBE2 (1500) - } \mathrm{p}^{*}\end{array}$ & $\begin{array}{ll}\cdot & \text { TBE1 (127) vs C (69) }-\mathrm{p}^{*} \\
\cdot & \text { TBE2 (192) vs C (69) - } \mathrm{p}^{\mathrm{a}} \\
\cdot & \text { TBE1 (127) vs TBE2 (192) - NS }\end{array}$ \\
\hline CXCL11 & $\begin{array}{ll}\cdot & \text { TBE1 (68) vs C (4.6) }-\mathrm{p}^{*} \\
\cdot & \text { TBE2 (26) vs C (4.6) - } \mathrm{p}^{\mathrm{a}} \\
\cdot & \text { TBE1 (68) vs TBE2 (26) - } \mathrm{p}^{*}\end{array}$ & $\begin{array}{ll}\text { - } & \text { TBE1 (80) vs C (91) - NS } \\
\text { - } & \text { TBE2 (132) vs C (91) - } \mathrm{p}^{\mathrm{a}} \\
\text { - } & \text { TBE1 (80) vs TBE2 (132) - NS }\end{array}$ \\
\hline $\begin{array}{c}\text { Koper et al., } 2018 \\
\text { TBE }(n=24) \text {, controls }(n=13)\end{array}$ & CSF & Serum \\
\hline CXCL9 & $\begin{array}{ll}\cdot & \text { TBE1 (215) vs C (6) }-\mathrm{p}^{*} \\
\cdot & \text { TBE2 (166) vs C (6) }-\mathrm{p}^{*} \\
\text { - } & \text { TBE1 (215) vs TBE2 (111) - NS }\end{array}$ & $\begin{array}{l}\text { - TBE1 (111) vs C (58)- } \mathrm{p}^{*} \\
\text { - } \text { TBE2 (138) vs C (58) - } \mathrm{p}^{*} \\
\text { - } \text { TBE1 (111) vs TBE2 (138) - NS }\end{array}$ \\
\hline
\end{tabular}

C - controls; CSF - cerebrospinal fluid; ELISA - enzyme-linked immunosorbent assay; $n$ - the number of subjects included in the study; NS - not statistically significant; ${ }^{a} \mathrm{p}$-value not presented in the paper; * $p$-value significantly higher $(p<0.05)$; TBE - tick-borne encephalitis; TBE1 - material of TBE patients tested at the time of diagnosis; TBE2 - material of TBE patients tested after follow-up. 
Approximately 15\% of the patients suffering from NB are affected by lymphocytic cerebrospinal meningitis. The coexistence of meningitis symptoms, painful radicular syndrome and cranial nerve paralysis is called Bannwarth syndrome. Myeloencephalitis develops with a much lower frequency (in about $0.1 \%$ of patients). ${ }^{23}$

Lepej et al. evaluated the contribution of chemokine receptor CXCR3 and its ligands CXCL10 and CXCL11 to the recruitment of peripheral blood memory CD4+ T cells into the CSF of patients with acute NB. ${ }^{24}$ In their studies, the percentage of memory CD45RO+CD4+ T cells expressing CXCR3 was significantly higher in the CSF compared to the peripheral blood. Additionally, concentrations of CXCL10 and CXCL11 in the CSF of NB patients were significantly higher compared to the corresponding serum samples. Regarding control samples, similar findings were observed only in the case of CXCL11. The authors suggested that in NB, CXCL10 and CXCL11 create a chemokine gradient between the CSF and serum, and recruit CXCR3-expressing memory CD4+ T cells into the CSF in patients with NB. ${ }^{24}$

Rupprecht et al. showed increased CXCL11 concentrations in the CSF of patients with NB as compared to the patients with noninflammatory CNS diseases. ${ }^{25}$ Additionally, in their studies, CSF CXCL11 concentrations were significantly correlated with white blood cell count (Table 2). They also found that CSF CXCL11 concentrations of NB patients are statistically more chemotactic for mononuclear cells than those of control patients and that the chemotactic index was correlated with the CSF white blood cell count. ${ }^{25}$

Henningsson et al. showed that patients with confirmed NB and possible early NB had significantly higher CSF concentrations of CXCL10 as compared to the non-NB group and the control group. ${ }^{26}$ Moreover, CSF CXCL10 correlated with CSF pleocytosis, but not with clinical parameters or the levels of anti-Borrelia-antibodies. In their opinion, time is probably an important factor for the chemokine profile, because Th1 cells dominate in the early stage of inflammation, which may be observed in patients with early NB. Thereafter, this response is counter-balanced by a Th2 response, which might be observed in patients with confirmed $\mathrm{NB}^{26}$ In the serum samples, CXCL10 concentrations were significantly higher in the confirmed NB group, as well as controls, as compared to subjects with possible early NB and the non-NB group. They also found that CSF CXCL10 concentrations did not correlate with the corresponding serum concentrations, which may indicate that the CSF is better material for the evaluation of the tested chemokine.

Moniuszko et al. revealed that pre-treatment serum CXCL10 and CXCL11 concentrations were significantly higher compared to the control group (Table 2). ${ }^{27}$ After treatment, only serum CXCL10 concentrations revealed statistically significant outcomes as compared to the controls. In the CSF, only pre-treatment and post-treatment CXCL11 concentrations were notably higher when compared to the control group (Table 2). The analysis of diagnostic usefulness showed that CXCL10 differentiates NB and controls, while CXCL11 can only distinguish between the pre-treatment NB cases and healthy subjects. ${ }^{27}$ According to Moniuszko et al., CXCL10 and CXCL11 are involved in the inflammatory process in NB; however, their results indicate that the chemokine patterns vary between the CSF and serum. ${ }^{27}$

The data in Table 2 indicates that both before and after antibiotic therapy, higher concentrations of CXCL10 in NB are noted in the CSF as compared to the serum samples. Data concerning the evaluation of the CXCL11 levels in NB is not coherent, thus this aspect requires further studies.

\section{Alzheimer's disease}

The most common form of dementia in elderly people is Alzheimer's disease (AD). ${ }^{28,29}$ About $70 \%$ of latelife mental failure is caused by $\mathrm{AD}$, which affects more than 25 million people worldwide. ${ }^{30}$ Of crucial relevance in the development of $\mathrm{AD}$ is the deposition of $\beta$ amyloid

Table 2. CXCL10 and CXCL11 tested by the ELISA method in neuroborreliosis. Values are expressed in $\mathrm{pg} / \mathrm{mL}$

\begin{tabular}{|c|c|c|}
\hline $\begin{array}{l}\text { Lepej et al., } 2005 \\
\text { Acute NB before AT } \\
(n=20) ; C(n=11)\end{array}$ & CSF & Serum \\
\hline CXCL10 & - $N B(733)$ vs C (9) - $\mathrm{p}^{*}$ & - $N B(155)$ vs C (99) - $p^{*}$ \\
\hline CXCL11 & - NB (17) vs C (70) - $\mathrm{p}^{*}$ & - NB (7) vs C (9) - NS \\
\hline \multicolumn{3}{|c|}{$\begin{array}{l}\qquad \text { Rupprecht et al., } 2005 \\
\text { Acute NB before AT }(n=17) ; C(n=20) \text { ELISA method }\end{array}$} \\
\hline CXCL11, CSF & \multicolumn{2}{|c|}{$\begin{array}{l}\text { - } N B(100) \text { vs } C(55)-p^{*} \\
\text { - } C X C L 11 \text { significantly correlated with the CSF cell count } \\
(p<0.001 ; r=0.57)\end{array}$} \\
\hline $\begin{array}{c}\text { Moniuszko et al., } 2014 \\
\text { Confirmed NB } \\
(\mathrm{n}=19) ; C(\mathrm{n}=8) \\
\text { ELISA method }\end{array}$ & CSF & Serum \\
\hline CXCL10 & $\begin{array}{ll}\text { - } & \text { NB1 (465) vs C (274) - NS } \\
\text { - } & \text { NB2 (441) vs C (274) - NS } \\
\text { - } & \text { NB1 (465) vs NB2 (441) - NS }\end{array}$ & $\begin{array}{ll}\cdot & \text { NB1 (333) vs C (70) }-\mathrm{p}^{*} \\
\text { - } & \text { NB2 (145) vs C (70) }-\mathrm{p}^{*} \\
\text { - } & \text { NB1 (333) vs NB2 (145) - } \mathrm{p}^{*}\end{array}$ \\
\hline CXCL11 & 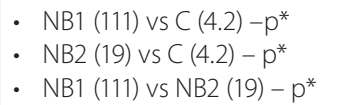 & $\begin{array}{ll}\text { - } & \text { NB1 (167) vs C (88) - } \mathrm{p}^{*} \\
\text { - } & \text { NB2 (105) vs C (88) - NS } \\
\text { - } & \text { NB1 (167) vs NB2 (105) - NS }\end{array}$ \\
\hline
\end{tabular}

AT - antibiotic therapy; C - controls; CSF - cerebrospinal fluid; ELISA - enzyme-linked immunosorbent assay; $\mathrm{n}$ - the number of subjects included in the study; NB1 - material tested before AT; NB2 - material tested after AT; NS - not statistically significant; * $p$-value significantly higher. 
(1-42) in association with neurofibrillary tangle (NFT) formation in the brain, which leads to irreversible neuronal damage (severe reduction in the brain weight of more than $35 \%$ post-mortem AD cases was noted). ${ }^{28,30}$

The literature widely emphasizes the role of inflammation in neurodegenerative disorders such as AD. The expression of inflammatory mediators in the affected brain regions of AD cases has been demonstrated. ${ }^{31}$ It was shown that in primary cortical neurons of mice, CXCL9 and CXCL10 were able to induce the activation of extracellular signal-regulated kinases (ERK1/2), which are members of the mitogen-activated-protein kinase. It is suggested that these chemokines might be involved in a neuronal-glial interaction. ${ }^{11}$ The up-regulation of chemokines and their receptors was also found in human AD brains. ${ }^{11,28}$

Xia et al. showed that CXCR3 regional pattern staining did not differ in AD as compared to the control brain tissues, with the exception of diminished neuronal staining in regions of marked neuronal loss in AD. ${ }^{11}$ Senile plaques of $\mathrm{AD}$ were not stained. Additionally, it was demonstrated that the CXCL10 expression defined a subpopulation of reactive astrocytes (the overall staining was higher in AD than in the controls). ${ }^{18}$

The CXCL10 over-expression in AD elicits apoptosis in fetal neurons. However, the mechanism of CXCL10mediated neurotoxicity is not clearly understood. Sui et al. demonstrated that the treatment of fetal neuron cultures with exogenous CXCL10 leads to the elevated levels of intracellular $\mathrm{Ca}^{2+}$ via the binding of CXCL10 to its receptor (CXCR3). ${ }^{32}$ Increased $\mathrm{Ca}^{2+}$, which is available for uptake by the mitochondria, is associated with membrane permeabilization, and cytochrome $\mathrm{c}$ is released from this compartment. In the next step, cytochrome $\mathrm{c}$ initiates active caspase-9, which sequentially activates the effector caspase-3. This directly leads to apoptosis. The authors suggested that their results may provide putative targets for pharmaceutical intervention. ${ }^{32}$

Galimberti et al. showed that CSF CXCL10 concentrations in $\mathrm{AD}$ patients, as well as in mild cognitive impairment subjects, were significantly higher compared to the controls (Table 3), which suggests a role of this chemokine in the early stage of the disease, during which inflammation is likely to be more pronounced. In AD subjects, CXCL10 also positively correlated with the mini-mental state examination (MMSE) ${ }^{28}$ However, further studies did not confirm their previous findings. They only indicated that the tested chemokine significantly correlated with age in the overall population. ${ }^{29}$

Corrêa et al. found a positive correlation between CXCL10 and $\beta$-amyloid in AD patients; however, CXCL10 concentrations did not differ in $\mathrm{AD}$ as compared to the controls (Table 3). ${ }^{33}$

The data included in Table 3 indicates that so far only CXCL10 concentrations have been analyzed in AD patients; however, the results obtained did not confirm the utility of the evaluation of this chemokine by the enzyme-linked immunosorbent assay (ELISA) method.

\section{Multiple sclerosis}

Multiple sclerosis (MS) attacks the myelinated axons in the CNS, and thus leads to the destruction of myelin and axons. The central mechanism of MS pathogenesis is the organ-specific traffic of $\mathrm{T}$ cells into the brain..$^{34}$

The genetic contribution to susceptibility to MS has been established. So far, 57 genetic loci associated with MS have been identified; however, the meta-analysis undertaken by O'Gorman et al. has shown that MS results from multiple genetic susceptibility factors and environmental factors. ${ }^{35}$ Kułakowska et al. analyzed 3,581 patients with MS (2,494 women and 1,030 men) and reported that a family history of MS was positive in only $6.4 \%$ of the cases. ${ }^{36}$

Research undertaken by Salmaggi et al. on microvascular endothelial cells and astrocytes from the human brain showed that CXCL9 behaved as a homing chemokine, while CXCL10 and CXCL11 were induced only after inflammatory stimuli. ${ }^{37}$ Additionally, CXCL10 statistically correlated with the CXCR3 expression on CSF CD4+ T cells. From among CXCL9, CXCL10 and CXCL11, probably only CXCL10 is involved in the maintenance of intrathecal inflammation in MS. . $^{38-40}$

It is widely accepted that the recruitment of leukocytes to the sites of inflammation is very important in MS pathology. In MS, activated T cells and macrophages cross through the BBB. To better understand the involvement

Table 3. CSF CXCL10 tested by the ELISA method in Alzheimer's disease. Values are expressed in $\mathrm{pg} / \mathrm{mL}$

\begin{tabular}{|c|c|}
\hline $\begin{array}{l}\text { Galimberti et al., } 2003 \\
\text { AD }(n=36) ; \mathrm{MCl}(n=38) \\
C(n=41)\end{array}$ & - $A D(103), M C l(128)$ vs C (69) - $p^{*}$ \\
\hline $\begin{array}{l}\text { Galimberti et al., } 2006 \\
\text { AD }(n=48) ; \mathrm{MCl}(n=36) ; \\
\text { C }(n=29)\end{array}$ & - $\mathrm{AD}$ (108) vs $\mathrm{MCl}(121)$ vs C (103) - NS \\
\hline $\begin{array}{c}\text { Corrêa et al., } 2011 \\
A D(n=22) ; C(n=27)\end{array}$ & - $A D$ vs $C-N S$ \\
\hline
\end{tabular}

AD - Alzheimer's disease; C - controls; CSF - cerebrospinal fluid; ELISA - enzyme-linked immunosorbent assay; $n$ - the number of subjects included in the study; NS - not statistically significant; $\mathrm{MCl}$ - mild cognitive impairment; * $p$-value significantly higher $(p<0.05)$.

Table 4. CSF CXCL10 tested by the ELISA method in multiple sclerosis Values are expressed in $\mathrm{pg} / \mathrm{mL}$

\begin{tabular}{cl} 
Sørensen et al., 2001 & \\
CDMS $(n=36) ;$ MON $(n=12) ;$ & $\cdot$ CDMS (2.6) vs C (1.8) - NS \\
$C(n=19)$ & CDMS (2.6) vs MON (2.1) - NS \\
\hline Mahad et al., 2002 & $\cdot$ MS, NIND and IND vs BH - $p^{*}$ \\
MS $(n=43) ;$ BH $(n=12) ;$ & $\cdot$ MS, IND vs NIND - p* \\
NIND $(n=44) ;$ IND $(N=24)$ & $\cdot$ MS vs IND - NS \\
\hline
\end{tabular}

$\mathrm{BH}$ - patients with benign headaches; C - controls; CDMS - clinically definite multiple sclerosis; CSF - cerebrospinal fluid; ELISA - enzymelinked immunosorbent assay; IND - inflammatory neurological diseases; $\mathrm{n}$ - the number of subjects included in the study; NIND - non-inflammatory neurological diseases; NS - not statistically significant; MON - monosymptomatic optic neuritis, ${ }^{*} \mathrm{p}$-value significantly higher. 
of chemokines in this mechanism, Simpson et al. examined post-mortem the CNS tissue from MS cases at different stages of lesion development. ${ }^{39}$ Based on their findings, Simpson et al. suggested a sequence of events which might occur in MS formation. In the first step, activated T cells in the perivascular environment express IFN- . Next, IFN- $\Upsilon$ induces the CXCL9 and CXCL10 expression in the surrounding glial cells, which finally selectively recruit further activated T-lymphocytes expressing CXCR3 to the site of inflammation. ${ }^{39}$

Mahad et al. showed significantly increased CXCL10 concentrations in the CSF of patients with MS, other inflammatory neurological diseases (IND) and non-inflammatory neurological diseases (NIND) as compared to subjects with benign headaches (control group). ${ }^{38}$ However, CXCL10 concentrations between MS and IND were not significantly different (Table 4). CXCL10 concentrations were also notably higher in patients with relapsing-remitting MS than in the case of secondary progressive MS, which means that CXCL10 tends to decrease over time following a clinical relapse, and suggests a role of this chemokine in the inflammatory and demyelinating processes involved in MS relapses. CXCL10 also correlated with the CXCR3 expression on CD4+ T cells from the CSF. The authors suggested that this correlation may be related to the chemoattractant role of CXCL10 for activated lymphocytes. ${ }^{38}$

The studies of Sørensen et al. indicated increased levels of CXCL10 in MS patients in comparison with controls; however these differences were not statistically significant (Table 4). ${ }^{41}$ CXCL10 concentration also did not change after 3 weeks of treatment (with methyloprednisolone or placebo). In their research, CXCL10 concentrations in the patients' group were positively correlated with the parameters of intrathecal inflammation, such as neopterin, MMP-9, leukocyte count, and intrathecal IgG and IgM synthesis. The correlation between CSF CXCL10 and leukocyte count was not observed in the control group; however, it should be noted that only 2 of the 19 control subjects had normal CSF leukocyte counts. The authors emphasized that their findings suggest a strong role of CXCL10 accumulation in acute CNS inflammation. On the other hand, they showed that CCL2 concentrations were significantly lower in the group of patients than in the controls. The aforementioned parameters also negatively correlated with the measures of inflammation, which may directly suggest that CXCL10 is likely involved in the maintenance of intrathecal inflammation. ${ }^{41}$

The data presented in Table 4 indicates that only CXCL10 was tested with the use of the ELISA method in MS; however, the results obtained are not cohesive.

\section{Conclusions}

The literature indicates the significant role of CXCL9, CXCL10, CXCL11, and their receptor (CXCR3) in the physiology and the pathophysiology of the CNS. Knowledge about the mechanism of action of CXCR3 and its ligands may be useful in the treatment of CNS diseases. However, literature data concerning the evaluation of CXCL9, CXCL10, CXCL11, and their receptor with the use of the ELISA method is limited. Available papers indicate that CXCL9 seems to be more specific for TBE than CXCL10 and CXC11, regardless of the type of patient material obtained for analysis (the CSF or serum). Data concerning NB indicates the importance of CXCL10 in this disease. Information regarding the evaluation of CXCL11 concentrations in NB is not coherent, so this aspect requires further study. From among the above-mentioned chemokines, so far only the CXCL10 levels have been analyzed in $\mathrm{AD}$; however, the studies have not proven the utility of the CXCL10 evaluation by means of the ELISA method. Similarly to AD, in MS, only CXCL10 has been analyzed so far, but the results obtained are not coherent.

\section{References}

1. Mazur G, Jaskuła E, Kryczek I, et al. Proinflammatory chemokine gene expression influences survival of patients with non-Hodgkin's lymphoma. Folia Histochem Cytobiol. 2011;49(2):240-247.

2. Banisadr G, Rostène W, Kitabgi P, Parsadaniantz SM. Chemokines and brain functions. Curr Drug Targets Inflamm Allergy. 2005;4(3):387-399.

3. Müller M, Carter S, Hofer MJ, Campbell IL. Review: The chemokine receptor CXCR3 and its ligands CXCL9, CXCL10, and CXCL11 in neuroimmunity - a tale of conflict and conundrum. Neuropathol Appl Neurobiol. 2010;36(5):368-387.

4. Ramesh G, MacLean AG, Philipp MT. Cytokines and chemokines at the crossroads of neuroinflammation, neurodegeneration, and neuropathic pain. Mediators Inflamm. 2013:480739. doi.org/10.1155/2013/480739

5. Clark-Lewis I, Mattioli I, Gong JH, Loetscher P. Structure-function relationship between the human chemokine receptor CXCR3 and its ligands. J Biol Chem. 2003;278(1):289-295.

6. Lazzeri E, Romagnani P. CXCR3-binding chemokines: Novel multifunctional therapeutic targets. Curr Drug Targets Immune Endocr Metabol Disord. 2005;5(1):109-118.

7. Bajetto A, Bonavia R, Barbero S, Florio T, Schettini G. Chemokines and their receptors in the central nervous system. Front Neuroendocrinol. 2001;22(3):147-184.

8. Bendall L. Chemokines and their receptors in disease. Histol Histopathol. 2005;20:907-926.

9. Sorce S, Myburgh R, Krause KH. The chemokine receptor CCR5 in the central nervous system. Prog Neurobiol. 2011;93(2):297-311.

10. Fernandez EJ, Lolis E. Structure, function, and inhibition of chemokines. Annu Rev Pharmacol Toxicol. 2002;42:469-499.

11. Xia MQ, Bacskai BJ, Knowles RB, Qin SX, Hyman BT. Expression of the chemokine receptor CXCR3 on neurons and the elevated expression of its ligand IP-10 in reactive astrocytes: In vitro ERK1/2 activation and role in Alzheimer's disease. J Neuroimmunol. 2000;108(1-2):227-235.

12. Zlotnik A, Yoshie O. Chemokines: A new classification system and their role in immunity. Immunity. 2000;12(2):121-127.

13. Li H, Gang Z, Yuling $H$, et al. Different neurotropic pathogens elicit neurotoxic CCR9- or neurosupportive CXCR3-expressing microglia. J Immunol. 2006;177(6):3644-3656.

14. Loetscher M, Loetscher P, Brass N, Meese E, Moser B. Lymphocytespecific chemokine receptor CXCR3: Regulation, chemokine binding and gene localization. Eur J Immunol. 1998;28(11):3696-3705.

15. Fulton AM. The chemokine receptors CXCR4 and CXCR3 in cancer. Curr Oncol Rep. 2009;11(2):125-131.

16. Lasagni L, Francalanci M, Annunziato F, et al. An alternatively spliced variant of CXCR3 mediates the inhibition of endothelial cell growth induced by IP-10, Mig, and I-TAC, and acts as functional receptor for platelet factor 4. J Exp Med. 2003;197(11):1537-1549.

17. Herpe B, Schuffenecker I, Pillot J, et al. Tick-borne encephalitis, southwestern France. Emerg Infect Dis. 2007;13(7):1114-1117. 
18. Bormane A, Lucenko I, Duks A, et al. Vectors of tick-borne diseases and epidemiological situation in Latvia in 1993-2002. Int J Med Microbiol. 2004;293(37):36-47.

19. Holub M, Klucková Z, Beran O, Aster V, Lobovská A. Lymphocyte subset numbers in cerebrospinal fluid: Comparison of tick-borne encephalitis and neuroborreliosis. Acta Neurol Scand. 2002;106(5):302-308.

20. Zajkowska J, Moniuszko-Malinowska A, Pancewicz SA, et al. Evaluation of CXCL10, CXCL11, CXCL12 and CXCL13 chemokines in serum and cerebrospinal fluid in patients with tick borne encephalitis (TBE). Adv Med Sci. 2011;56(2):311-317.

21. Koper OM, Kamińska J, Grygorczuk S, Zajkowska J, Kemona H. CXCL9 concentrations in cerebrospinal fluid and serum of patients with tickborne encephalitis. Arch Med Sci. 2018;14(2):313-320.

22. Hubálek Z. Epidemiology of Lyme borreliosis. Curr Probl Dermatol. 2009;37:31-50.

23. Henningsson AJ, Malmvall BE, Ernerudh J, Matussek A, Forsberg P. Neuroborreliosis - an epidemiological, clinical and healthcare cost study from an endemic area in the south-east of Sweden. Clin Microbiol Infect. 2010;16(8):1245-1251.

24. Lepej SZ, Rode OD, Jeren T, Vince A, Remenar A, Barsić B. Increased expression of CXCR3 and CCR5 on memory CD4+ T-cells migrating into the cerebrospinal fluid of patients with neuroborreliosis: The role of CXCL10 and CXCL11. J Neuroimmunol. 2005;163(1-2): 128-134.

25. Rupprecht TA, Koedel U, Muhlberger B, Wilske B, Fontana A, Pfister HW. CXCL11 is involved in leucocyte recruitment to the central nervous system in neuroborreliosis. J Neurol. 2005;252(7):820-823.

26. Henningsson AJ, Tjernberg I, Malmvall BE, Forsberg P, Ernerudh J. Indications of Th1 and Th17 responses in cerebrospinal fluid from patients with Lyme neuroborreliosis: A large retrospective study. J Neuroinflammation. 2011;20:8-36.

27. Moniuszko A, Czupryna P, Pancewicz S, et al. Evaluation of CXCL8, CXCL10, CXCL11, CXCL12 and CXCL13 in serum and cerebrospinal fluid of patients with neuroborreliosis. Immunol Lett. 2014;157(1-2):45-50.

28. Galimberti D, Schoonenboom N, Scarpini E, Scheltens P; Dutch-Italian Alzheimer Research Group. Chemokines in serum and cerebrospinal fluid of Alzheimer's disease patients. Ann Neurol. 2003;53(4):547-548.

29. Galimberti D, Schoonenboom N, Scheltens P, et al. Intrathecal chemokine levels in Alzheimer disease and frontotemporal lobar degeneration. Neurology. 2006;66(1):146-147.

30. Farfara D, Lifshitz V, Frenkel D. Neuroprotective and neurotoxic properties of glial cells in the pathogenesis of Alzheimer's disease. J Cell Mol Med. 2008;12(3):762-780.

31. Schwab C, McGeer PL. Inflammatory aspects of Alzheimer disease and other neurodegenerative disorders. J Alzheimers Dis. 2008;13:359-369.

32. Sui Y, Stehno-Bittel L, Li S, et al. CXCL10-induced cell death in neurons: Role of calcium dysregulation. Eur JNeurosci. 2006;23(4):957-964.

33. Corrêa JD, Starling D, Teixeira AL, Caramelli P, Silva TA. Chemokines in CSF of Alzheimer's disease patients. Arq Neuropsiquiatr. 2011;69(3):455-459.

34. Goldenberg MM. Multiple sclerosis review. P\&T. 2012;37(3):175-184.

35. O'Gorman C, Lin R, Stankovich J, Broadley SA. Modelling genetic susceptibility to multiple sclerosis with family data. Neuroepidemiology. 2013;40(1):1-12.

36. Kułakowska A, Bartosik-Psujek H, Hożejowski R, Mitosek-Szewczyk K, Drozdowski W, Stelmasiak Z. Wybrane aspekty epidemiologiczne stwardnienia rozsianego w Polsce - wieloośrodkowe badanie pilotażowe. Neurol Neurochir Pol. 2010;44(5):443-452.

37. Salmaggi A, Gelati $M$, Dufour $A$, et al. Expression and modulation of IFN-gamma-inducible chemokines (IP-10, Mig, and I-TAC) in human brain endothelium and astrocytes: Possible relevance for the immune invasion of the central nervous system and the pathogenesis of multiple sclerosis. J Interferon Cytokine Res. 2002;22(6):631-640.

38. Mahad DJ, Howell SJ, Woodroofe MN. Expression of chemokines in the CSF and correlation with clinical disease activity in patients with multiple sclerosis. J Neurol Neurosurg Psychiatry. 2002;72(4):498-502.

39. Simpson JE, Newcombe J, Cuzner ML, Woodroofe MN. Expression of the interferon-gamma-inducible chemokines IP-10 and Mig and their receptor, CXCR3, in multiple sclerosis lesions. Neuropathol Appl Neurobiol. 2000;26(2):133-142.
40. Balashov KE, Rottman JB, Weiner HL, Hancock WW. CCR5(+) and CXCR3(+) T cells are increased in multiple sclerosis and their ligands MIP-1alpha and IP-10 are expressed in demyelinating brain lesions. Proc Natl Acad Sci USA. 1999;96(12):6873-6878.

41. Sørensen TL, Sellebjerg F, Jensen CV, Strieter RM, Ransohoff RM. Chemokines CXCL10 and CCL2: Differential involvement in intrathecal inflammation in multiple sclerosis. Eur J Neurol. 2001;8(6):665-672. 